\title{
Cacicazgo y Revolución en la Huasteca veracruzana
}

Ricardo Pérez Montfort

\section{Manuel Peláez y la vida rural en la Faja de Oro. Petróleo, revolución y sociedad en el norte de Veracruz, 1910-1928}

Instituto Mora, México, 362 pp.

E $\mathrm{n}$ algún momento entre mayo $\mathrm{y}$ junio de 1926, el general constitucionalista Francisco J. Mújica, entonces un tanto abandonado a su suerte, escribió en su diario:

Luchando por la vida vuelvo a estas regiones devorantes de hombres y pródiga en frutos. Me atrae la Huasteca por su riqueza incomparable y su naturaleza africana. Hay mucho petróleo y hermosas puestas

de sol; insectos dañinos, fiebres malignas y arteros pantanos, en sus bosques interminables donde entona el ramaje estrofas sublimes en sus frutos, en sus flores [...] Cuando voy por sus trochas violatrices camino al ensueño, si huello sus laderas esmeralda, me admiran sus ganados, lisos como la porcelana, suaves como la seda [...] $\mathrm{Al}$ surcar sus ríos se encoje el espíritu y si llueve en la montaña el diluvio es imponente. Sus aguas

\section{Boss Rule and Revolution in the Huasteca Veracruzana}

RICARDO PÉREZ MONTFORT: Centro de Investigaciones y Estudios Superiores en Antropología Social-Distrito Federal, México rpmont54@yahoo.com.mx

Desacatos, núm. 34, septiembre-diciembre 2010, pp. 177-181

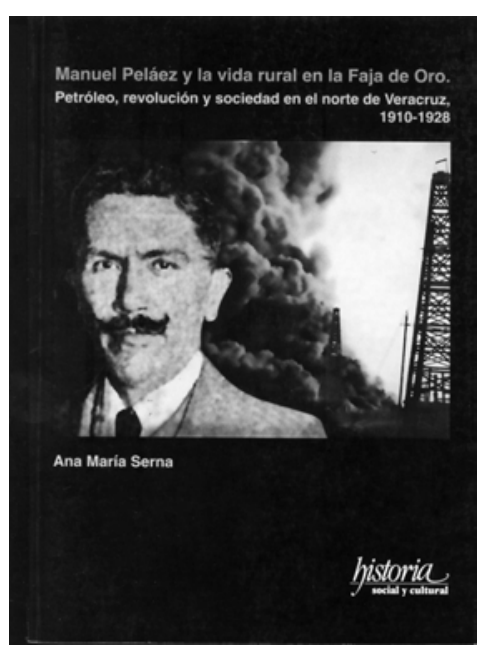

broncas, alud que nada detiene y el rugido de la tempestad parece un himno (Mújica, 1984).

El general se encontraba en aquellos rumbos tratando de rehacer su vida, después de un particular desencuentro con los caudillos sonorenses que casi le cuesta la existencia. Al parecer, siendo gobernador de 


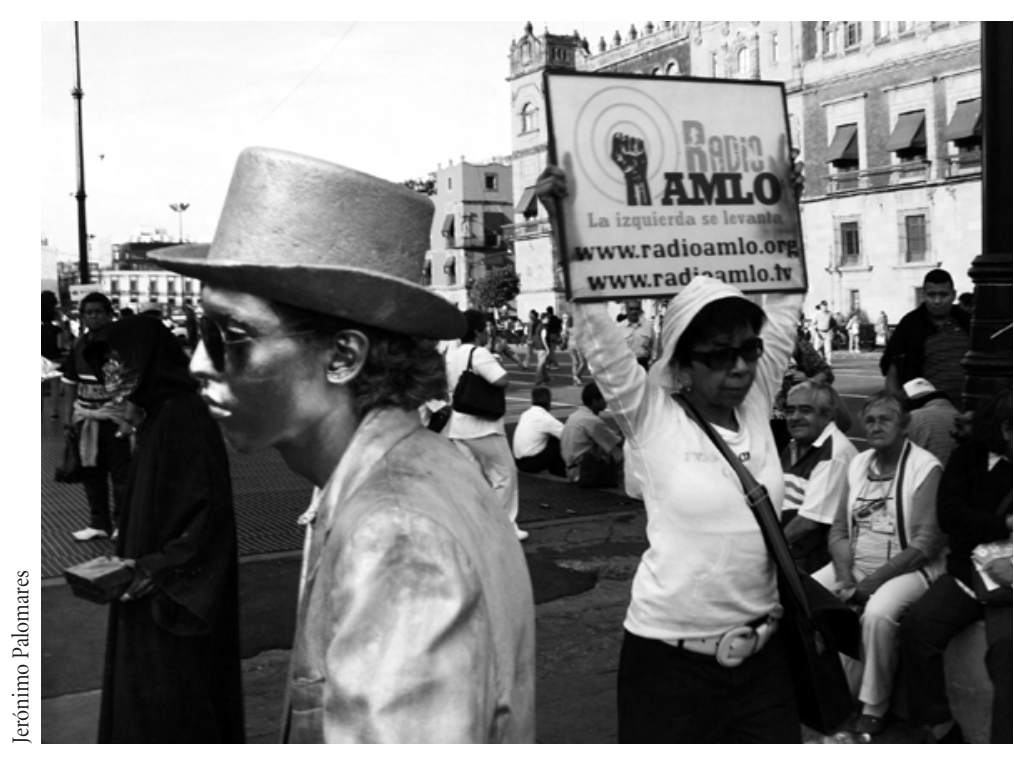

Radio AMLO, 2008.

Michoacán, el mismísimo Álvaro Obregón lo había mandado matar, debido a sus constantes insubordinaciones al poder central (De Maria y Campos, 1939). Después de permanecer escondido durante un par de años, decidió retornar a la vida civil, aunque su inquietud lo volvió a poner en la brega, si no revolucionaria por lo menos reflexiva: se mantuvo particularmente atento a los acontecimientos que iban moldeando el desarrollo político y económico del país. Contratado como miembro de un despacho de abogados para investigar y tratar de resolver un fraude petrolero, Mújica recorrió aquella región de la Huasteca dejando una serie de notas líricas y ricas en puntuales descripciones. Entre sus muchas referencias al paisaje natural y humano destaca la siguiente que describe con precisión la situación local:
Casucas de madera, algunas de piedra y otras de enjarre (varas y lodo), ingeniosamente combinadas, forman el caserío. Una escuela y el Palacio Municipal, regalos de la compañía petrolera, son las magníficas fincas del poblado, de madera y lámina, con sus ventanales alambrados. La población es indígena pura y hablan "mexicano" en todos sus asuntos; tienen en sus manos el Gobierno Municipal y están armados. Casi todos son propietarios y reciben rentas por tener arrendadas sus tierras a compañías petroleras (Mújica, 1984).

El interés y la inquietud de Mújica por conocer la problemática regional lo llevó a escudriñar los intrincados recovecos de la historia local reciente, en la cual aparecía constantemente una figura clave: el cacique rebelde Manuel Peláez. Mújica ya había tenido noticias de aquel hombre fuerte de la Huasteca, por lo menos desde la segunda mitad de la década anterior, cuando el michoacano tuvo que lidiar con las compañías petroleras que se disputaban la explotación de ciertos yacimientos recién descubiertos en la frontera de Veracruz y Tabasco. Como gobernador constitucionalista de este último estado, Mújica no simpatizó con la alianza que Peláez manifestó abiertamente al cuidar e incluso defender los intereses de las compañías petroleras de la Huasteca. Como buen ideólogo revolucionario, Mújica vio esta alianza como consecuencia de los intereses familiares de los Peláez, vinculados desde finales del siglo XIX con el Porfiriato y su connotada condición de “vendepatrias". El espíritu nacionalista y la postura anticaciquil de Mújica quedaron anotados en su diario el 28 de junio de aquel 1926 con las siguientes frases:

De mañana montamos rumbo a Temapache. Reconstruimos las etapas de la lucha pelaecista. Por estas brechas caminaba el rebelde cómplice de las compañías. Sus dominios llegaban a Cerro Azul y Casiano, Potrero y Tierra Blanca, Temapache y Tierra Amarilla eran de su propiedad. El riñón del petróleo estaba en su poder. Dinero y armas eran sus aliados. ¿Qué peleaba este rebelde? Se trataba de nacionalizar el petróleo. Esto era un golpe a la voracidad del yanqui y Peláez, propietario de un mal pozo en Tierra Amarilla, fue el instrumento de la oposición. En ese tiempo abundaban los hombres en los campos de petróleo y tuvo el traidor brazos en abundancia. Peláez es nativo de Temapache, 
pueblo próspero y pintoresco entonces. Hoy es una ruina, asolado por la guerra, muerto por la dispersión (Mújica, 1984).

Esta situación, según Mújica, era producto claro de quienes como Peláez habían traicionado a su gente, a su país y a la propia Revolución para aliarse con los intereses yanquis, $y$ con su apoyo convertirse en hombres fuertes de su región, satisfaciendo su ambición personal. En su paso por Temapache, el ex general constitucionalista reportó la imagen de un pueblo acabado al que le quedaban algunas construcciones y una parroquia en ruinas por culpa de caciques como los Peláez:

Don Anastasio de la Cruz, viejo
indio de 64 años, secretario del
ayuntamiento y nada tonto, me dice
con tristeza: "si se cae la parroquia,
se extinguirá el pueblo". La gente
que hay ha vuelto sólo por eso.
Este viejito me enseña las casas
quemadas del pueblo; en una
grande nació el cabecilla; en otra
los Peraltas. Ambas familias son
multimillonarias hoy. ¿Han hecho
algo por el pueblo?, pregunto. ¡Ah
sí! Los señores Peralta nada. Don
Manuel arruinarlo en su rebeldía.
(Mújica, 1984).

Para entonces, Manuel Peláez se encontraba prácticamente ausente del quehacer político caciquil y vivía cómodamente entre Estados Unidos y la ciudad de México. Si bien aún mantenía estrecha relación con las compañías petroleras y permanecía atento a los conflictos entre éstas y el general Calles y su gabinete, lo cierto

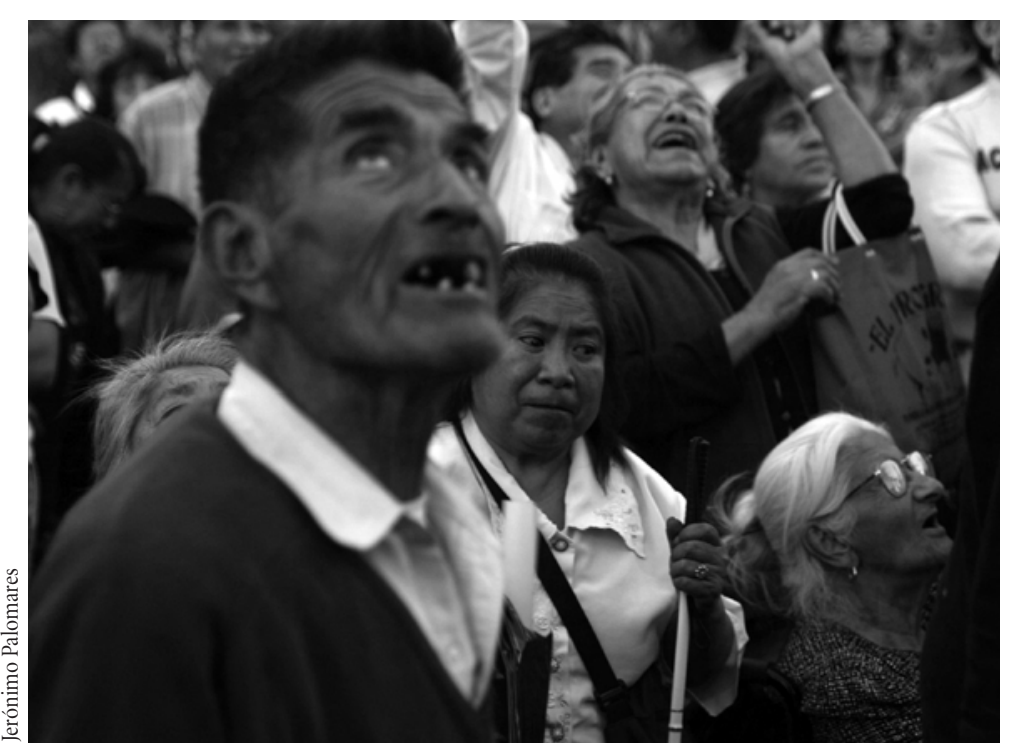

Sin título, 2008.

es que su época de gloria entre disputas y compromisos ya había pasado. Viviría casi 50 años más, hasta 1971, de sus rentas y negocios,

habiendo hecho unas extrañas paces con los gobiernos posrevolucionarios.

Hasta hace muy poco, las referencias a Manuel Peláez y su condición de cacique financiado por las compañías petroleras durante la Revolución fueron muy parecidas a las que Mújica anotó en aquel 1926. Los trabajos de Heather Fowler (1979) y Javier Garciadiego (1981) parecían corroborar la idea de que se trataba de un "contrarrevolucionario" que mal que bien podía reducirse a una figura convenenciera y oportunista, que se mantuvo al servicio de las compañías petroleras y se opuso constantemente a la implementación de la política nacionalista del constitucionalismo. Jonathan Brown (1993) e Isela Santiago (1997) habían insis- tido en que el movimiento pelaecista en la Huasteca veracruzana tenía una importante serie de características propias que lo hacía difícil de reducir a una caracterización generalizadora.

Pero he aquí que con el trabajo de Ana María Serna, Manuel Peláez y la vida rural en la Faja de Oro. Petróleo, revolución y sociedad en el norte de Veracruz, 1910-1928, editado por el Instituto Mora en 2008, tanto la figura de Peláez como las circunstancias en las que le tocó vivir adquieren una nueva dimensión, mucho más acorde con lo que podríamos considerar como la de "un hombre de carne y hueso", con visos propios, contextos e intereses mucho más precisos, y como cualquier otro ser humano, pleno de contradicciones.

Siguiendo una estructura bastante ortodoxa, el libro de Ana María Serna va de lo general a lo particular, de la historia regional a la local, de ahí 
a la vida familiar y a la individual, logrando lo que en antropología se ha identificado como "una descripción densa" o, si se quiere, una especie de etnografía del contexto social, económico y cultural en el que estuvo inmerso Manuel Peláez durante sus 18 años de mayor actividad como figura política regional. En este sentido, la reconstrucción histórica del entorno en que se desarrolló este individuo que fue autoridad militar informal aunque legítima, que contó con bastante apoyo popular y fungió de intermediario entre terratenientes, compañías petroleras, intereses obreros y de grupos políticos se logra de manera muy convincente y adquiere nuevos ángulos capaces de replantear las mencionadas generalizaciones.

En primer lugar, el libro arranca con una descripción minuciosa del espacio y las principales actividades económicas en los tiempos precedentes a la Revolución. Presenta de manera pormenorizada la situación en la Huasteca y el norte de Veracruz, mostrando las ransformaciones agrarias específicas que dicha región vivió durante el Porfiriato y que hicieron posible la aparición de estos terratenientes, representados por la familia Peláez. Siguiendo a David Skerrit (2003) se intenta definir a estos rancheros independientes como actores principales de los cambios agrarios en la zona, en oposición a las comunidades indígenas que no se aferraron tanto a las formas tradicionales de propiedad y usufructo de la tierra, y que fueron beneficiadas por los condueñazgos. Esta categoría resulta puntualmente definitoria, pues determina tanto las relaciones de producción como las sociales. Así, la ausencia de un conflicto agrario radical hizo de la Huasteca veracruzana un espacio propicio para el surgimiento del cacicazgo de Peláez, justo a finales del Porfiriato.

La aparición de las compañías petroleras también contribuyó a este hecho. La misma autora lo confirma al decir que tres fueron los factores que hicieron de Peláez un cacique inusual: "una historia familiar arraigada en el prestigio local basado, por una parte, en una buena relación con los grupos populares; una fuerte red familiar, y una extraordinaria capacidad para hacer tratos con extranjeros, combinada con la habilidad para sacar el mayor beneficio de su papel de intermediario" (p. 91). De esta manera, Peláez ocupó un lugar que, mal que bien, debía corresponderle a los grupos evolucionarios y sus autoridades, con la venia de los petroleros, los trabajadores, los terratenientes y las comunidades. Fue un personaje que, por así decirlo, usurpó el espacio que los gobiernos de la Revolución se habían otorgado a sí mismos. Ellos debieron brindar, como lo planteaban sus principios fundamentales, la seguridad a la hora de fomentar los cambios sociales. Sin embargo, quien proporcionó esta seguridad fue Peláez, y de ahí la fuerza de su cacicazgo.

A lo largo del libro esta tesis va quedando cada vez más clara. Primero durante la última etapa del Porfiriato, después con Francisco I. Madero y finalmente con Venustiano Carranza, la emergencia del pelaecismo se explica a partir de esa condición de intermediario entre región y poderes estatales, entre legitimidad local y voracidad extranjera, entre nacionalismos radicales y defensa de los intereses lugareños. Tal vez esa misma condición explique la volatilidad de sus alianzas convencionistas, su pseudovillismo, su coqueteo con el zapatismo y, por último, su definición específica como pelaecismo. Las circunstancias de la guerra mundial y su posición frente al cada vez más relevante recurso estratégico, el petróleo, terminan por convertir a Peláez en figura imprescindible para propios y extranjeros. Los gobiernos de los caudillos revolucionarios se dieron cuenta de que el general huasteco también les podía ser bastante útil y terminaron por incluirlo en la nómina.

Sin embargo, Ana María Serna no se queda en ese punto, sino que analiza el fenómeno regional de la Huasteca revolucionaria, las acciones concretas de las compañías petroleras y, específicamente, el pelaecismo y su relación con los gobiernos revolucionarios, con elementos que resultan muy comparables, a mi juicio, con lo que sucede actualmente en muchas regiones del país: la emergencia de "nuevos ricos" con fuertes tendencias caciquiles, de los cuales Peláez podría ser un muy buen representante, y de quienes hoy tenemos varios ejemplos vivos: los Peralta en el norte del Estado de México o los Bravo Ahuja en el Alto Papaloapan, tan sólo por mencionar 
dos casos. Son personajes con claras afinidades extranjerizantes frente al nacionalismo, puntualmente acomodaticios ante las adversidades externas, pero sobre todo sustancialmente oportunistas y conservadores, que logran mantener la cabeza a flote en múltiples circunstancias, comprometidos con su propio bienestar y con un discurso inclusivo y notablemente demagógico. No son sólo mercenarios, como tampoco lo fue Peláez, y al parecer responden a cierta legitimidad local, pero difícilmente ven más allá de su propio beneficio y de sus negocios. Al igual que muchos fenómenos populares, incluyendo el nacionalismo, tan caro para muchos mexicanos, la volatilidad de sus alianzas y lo manipulable de sus expectativas termina mostrando su enorme falta de consistencia. Son sus intereses particulares los que dominan su existencia, no tanto los beneficios de las mayorías o su apego a las demandas sociales. Así, Peláez resulta un personaje que defendió sus propios intereses y que gozó de cierta legitimidad, pero a su paso por la Huasteca veracruzana las cosas cambiaron poco y no generó mucho provecho popular que digamos.

En ese sentido, el reclamo de quienes tuvieron y representaron ciertos ideales, como el general Mújica, notables perdedores de la Revolución, parece seguir vivo y embona puntualmente con estos versos de Paco Píldora ${ }^{1}$ irreverentemente enmenda-

\footnotetext{
${ }^{1}$ Paco Píldora fue el alias de Francisco Rivera Ávila, quien durante buena parte del siglo XX fue considerado como el cronista popular del puerto de Veracruz.
}

dos, pero que bien pueden rematar esta brevísima reseña:

Está el Veracruz actual de tanta mugre embarrado que de uno a otro lado el aspecto sigue igual; en el centro, el arrabal es todo mugre y basura, bache y descalabradura y un suave aroma de hampón. Le falta mucho jabón escoba, lejía y pintura...

Pero el pueblo sigue igual viviendo en la mansedumbre,

la ruina, la podredumbre y el abandono total. Es ya su vivir usual cambiarlo parece tontera; ha sido larga la espera y tan nulo el resultado que sigue mudo, amarrado ante tanta... fregadera.

\section{Bibliografía}

Brown, Jonathan C., 1993, Oil and Revolution in Mexico, University of California Press, Berkeley.

De Maria y Campos, Armando, 1939, Mújica, Crónica biográfica, cep, México.

Fowler Salamini, Heather, 1979, Movilización campesina en Veracruz, 1920-1938, Siglo XXI, México.

Garciadiego Dantán, Javier, 1981, "Revolución constitucionalista y contrarrevolución (movimientos reaccionarios en México 1914-1920)", tesis doctoral, El Colegio de México, México, inédito.

Mújica, Francisco J., 1984, “Su paso por la Huasteca veracruzana", Desdeldiez, Boletín del Centro de Estudios de la Revolución Mexicana “Lázaro Cárdenas" A. C., septiembre, Jiquilpan, Michoacán.
Santiago, Myrna Isela, 1997, "Huasteca Crude: Indians, Ecology, and Labor in the Mexican Oil Industry: Northern Veracruz, 1900-1938", tesis de doctorado, Universidad de California, Berkeley.

Skerritt, David G., 2003, Una historia agraria del centro de Veracruz 1850-1940, Universidad Veracruzana, Xalapa. 